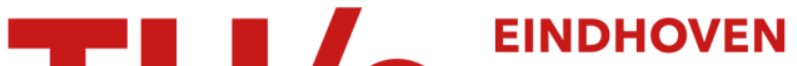 \\ UNIVERSITY OF \\ TECHNOLOGY
}

\section{Lateral torsional buckling design imperfections for use in non- linear FEA}

Citation for published version (APA):

Snijder, H. H., van der Aa, R. P., Hofmeyer, H., \& van Hove, B. W. E. M. (2018). Lateral torsional buckling design imperfections for use in non-linear FEA. Steel Construction, 11(1), 49-56.

https://doi.org/10.1002/stco.201810015

DOI:

10.1002/stco.201810015

Document status and date:

Published: 01/02/2018

Document Version:

Accepted manuscript including changes made at the peer-review stage

Please check the document version of this publication:

- A submitted manuscript is the version of the article upon submission and before peer-review. There can be important differences between the submitted version and the official published version of record. People interested in the research are advised to contact the author for the final version of the publication, or visit the $\mathrm{DOI}$ to the publisher's website.

- The final author version and the galley proof are versions of the publication after peer review.

- The final published version features the final layout of the paper including the volume, issue and page numbers.

Link to publication

\section{General rights}

Copyright and moral rights for the publications made accessible in the public portal are retained by the authors and/or other copyright owners and it is a condition of accessing publications that users recognise and abide by the legal requirements associated with these rights.

- Users may download and print one copy of any publication from the public portal for the purpose of private study or research.

- You may not further distribute the material or use it for any profit-making activity or commercial gain

- You may freely distribute the URL identifying the publication in the public portal.

If the publication is distributed under the terms of Article 25fa of the Dutch Copyright Act, indicated by the "Taverne" license above, please follow below link for the End User Agreement:

www.tue.nl/taverne

Take down policy

If you believe that this document breaches copyright please contact us at:

openaccess@tue.nl

providing details and we will investigate your claim. 


\section{Lateral torsional buckling design imper- fections for use in non-linear FEA}

To perform geometrically and materially nonlinear analyses including imperfections for steel beam lateral torsional buckling, the size and shape of the geometric imperfection can be obtained from EN 1993-1-1. The shape is prescribed as an initial bow along the weak axis of the section, excluding torsion of the cross-section. The shape of the imperfection can alternatively be taken equal to the lateral torsional buckling mode, including torsion. Several tables and formulas exist to determine the size of the imperfection. In this article, different imperfection approaches are presented for finite element simulations to evaluate the lateral torsional non-linear buckling resistances and to compare these to the results obtained with design rules. Based on the comparisons made, the article concludes with a proposal for design imperfections to be used in non-linear Finite Element Analyses (FEA) for lateral torsional buckling of beams.

\section{Introduction}

Eurocode 3 provides design rules for the assessment of lateral torsional buckling (LTB) of beams in bending in clause 6.3.2 of EN 1993-1-1 [1]. Alternatively, the code allows LTB to be assessed by performing Geometrically and Materially Nonlinear Analyses with Imperfections of beams. For carrying out such GMNIA calculations, the size and shape of the equivalent geometric imperfection is given in clause 5.3.4(3) of EN 1993-1-1. The shape is prescribed as an equivalent initial bow of the weak axis of the section considered, excluding torsion of the cross-section. This comes down to the weak axis flexural buckling (FB) mode. The size is prescribed as $k \cdot e_{0, d}$ where $k$ is a factor having as recommended value $k=$ 0.5 and $e_{0, d}$ is the initial local bow imperfection given in Table 5.1 of EN 1993-1-1. This initial local bow imperfection depends on column length, relevant buckling curve and the type of cross-section check used (elastic or plastic). The design values of the initial local bow imperfections as given in Table 5.1 of EN 1993-1-1 are under debate [2]. In [2] it is shown that the values specified are sometimes unconservative and a new proposal [3] has been made and adopted for inclusion in the next version of EN 1993-1-1. In the new proposal, the initial local bow imperfection also depends on yield stress level besides on column length, relevant buckling curve and the type of cross-section check used. Further restricting design rules are given for the case that a plastic cross-section check is used. As an alternative to the initial local bow imperfections of Table 5.1 of EN 1993-1-1 and of the new proposal, the initial local bow imperfection $e_{0, d}$ can be more accurately based on the slenderness dependent eq. (5.10) of EN 1993-1-1:

$e_{0, d}=\alpha(\bar{\lambda}-0.2) \frac{M_{R k}}{N_{R k}}$

Where $\alpha$ is the imperfection factor according to Table 6.1 of EN 1993-1-1, $\bar{\lambda}$ is the non-dimensional slenderness for weak axis buckling, $M_{R k}$ is the characteristic moment resistance, and $N_{R k}$ is the characteristic normal force resistance. In case of class 1 and 2 cross-sections $M_{R k}=M_{p l}$ and $N_{R k}=N_{p l}$ where $M_{p l}$ is the plastic moment resistance of the cross-section and $N_{p l}$ is its plastic normal force resistance.

The advantage of the initial local bow imperfections of Table 5.1 of EN 1993-1-1 and of the new proposal 
is that they are independent of slenderness. They can therefore be easily applied in all kinds of second order analyses. However, if it is the intention to carry out GMNIA calculations by FEA, the slenderness can easily be calculated from the results of a LBA by using the same FE model as for the GMNIA. Then Eq. (1) can be applied equally easily.

In line with clause 5.3.2(11) of EN 1993-1-1, the shape of the imperfection can also be taken according to the LTB mode, including torsion of the cross-section. For the size of the imperfection, Eq. (1) can be used. However, for the next generation of Eurocodes, new LTB design rules [4-8] have been derived consistently as an alternative to those of the current EN 1993-1-1. Using these new LTB design rules and their derivation, a formula has been obtained which, for an LTB mode, describes explicitly the imperfection size:

$e_{0, d}=\alpha_{L T}\left(\bar{\lambda}_{L T}-0.2\right) \frac{M_{R k}}{N_{R k}}$

Where $\alpha_{L T}$ is the imperfection factor according to Table 1 (also see [8]) and $\bar{\lambda}_{L T}$ is the non-dimensional slenderness for lateral torsional buckling. In Table $1, h$ is the section height, $b$ is the section width and $W_{e l, y}$ and $W_{e l, z}$ are the strong and weak axis section modulus respectively.

Table 1: Imperfection factors for Eq. (2)

\begin{tabular}{|c|c|c|}
\hline Cross-section & Limits & $\alpha_{L T}$ \\
\hline \multirow{2}{*}{ Rolled I-section } & $h / b>1.2$ & $0.12 \sqrt{W_{e l, y} / W_{e l, z}} \leq 0.34$ \\
\cline { 2 - 3 } & $h / b \leq 1.2$ & $0.16 \sqrt{W_{e l, y} / W_{e l, z}} \leq 0.49$ \\
\hline
\end{tabular}

Table 2: Three imperfection approaches

\begin{tabular}{|c|c|c|}
\hline Approach & Imperfection shape & Imperfection size \\
\hline 1 & Weak axis FB mode, excluding torsion & $k \cdot e_{0, d}$ of Eq. (1) \\
\hline 2 & LTB mode, including torsion & $k \cdot e_{0, d}$ of Eq. (1) \\
\hline 3 & LTB mode, including torsion & $e_{0, d}$ of Eq. (2) \\
\hline
\end{tabular}

The three different imperfection approaches for LTB as shown in Table 2 have been studied in this article. A finite element model for LTB was developed and verified using several other models in literature. With that model, the different approaches for imperfection shape and size were applied to evaluate the LTB resistances by GMNIA. Subsequently, these LTB resistances were compared with the LTB resistances according to the appropriate design rules. For the approaches 1 and 2, the design rules according to the clauses 6.3.2.1 and 6.3.2.2 of EN 1993-1-1 for the so called 'general case' were used as reference while for approach 3 the newly developed design rules according to [4-8] were used. This article is based on research work as reported in [9] and is an extended and updated version of the conference paper [10].

\section{Scope}

The imperfection study in this article is carried out for hot-rolled class 1 and 2 IPE, HEA, and HEB sections. The fillet radius between web and flanges is neglected; therefore the sections are denoted by adding an asterisk: e.g. IPE* sections. The section properties have been modified accordingly for proper comparisons. Three load cases have been considered as indicated in Fig. 1.
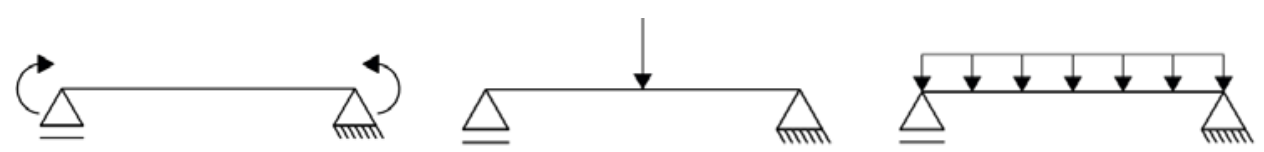

Fig. 1: Three load cases (LC) considered: LC1 - constant bending moment (left), LC2 - concentrated load (middle), LC3 - uniformly 


\section{Finite element model}

For the finite element model, developed in Abaqus 6.2 [11], so-called "S8R" Mindlin-Reissner elements are used. These are quadrilateral eight node shell elements with six degrees of freedom (DOF's) per node, four integration points across the surface, and five integration points ("section points" in Abaqus) along the thickness. The elements take into account shear deformations and thus are suitable for thick shell applications. A mesh-convergence study led to the application of 8 elements over the width of the flanges and 16 elements over the height of the web. A bilinear stress-strain diagram, neglecting strain hardening, is used with yield stress $f_{y}=235 \mathrm{~N} / \mathrm{mm}^{2}$ and Young's modulus $E=2.1 \times 10^{5} \mathrm{~N} / \mathrm{mm}^{2}$. The Poisson's ratio is set to 0.3 . The Von Mises yield criterion was applied.
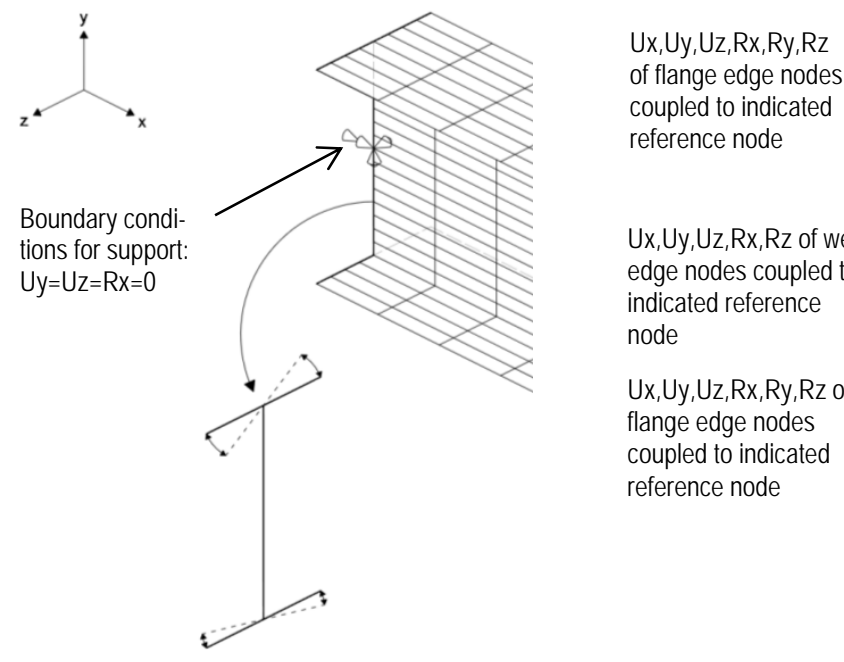
coupled to indicated reference node

Ux,Uy,Uz,Rx,Rz of web edge nodes coupled to indicated reference node

Ux,Uy,Uz,Rx,Ry,Rz of flange edge nodes coupled to indicated reference node

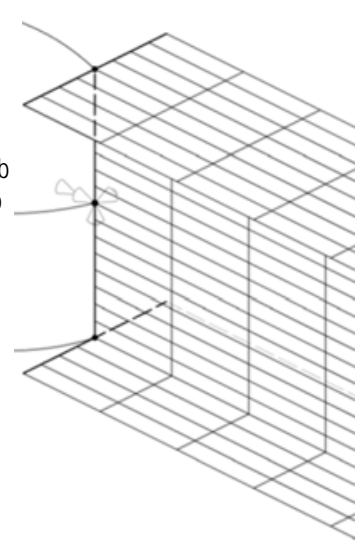

Fig. 2: Boundary conditions for support on the left, kinematic coupling constraints for the cross-section on the right.

With respect to the boundary conditions, Fig. 2 on the left shows three bold lines that indicate the left end of the web and flanges, in other words the lines of the cross-section at the complete left. Using so-called kinematic coupling constraints, all finite element nodes at the bold line of the top flange are coupled for all their displacements and rotations to a reference node: the node at the middle of this line, and the same applies to the bottom flange. This effectively makes the lines of the flanges infinitely stiff. For the web, all nodes at the bold line are coupled for all their displacements - and only for rotations about the $x$ and $z$ axis - to a reference node at the middle of the line. As such these constraints result in a cross-section which is infinitely stiff in-plane, but able to warp (limited to straight flange lines) as is shown in the bottom left part of Fig. 2. Note that "in geometrically non-linear analysis steps, the coordinate system in which the constrained degrees of freedom are specified will rotate with the reference node" [11].

Secondly, for fixing the beam in place, boundary conditions are applied to set displacements in $y$ and $z$ direction and rotations about the $x$-axis zero, see Fig. 22 on the left.

Since beam geometry, load cases, imperfection shapes, and failure modes are symmetrical, only half the beam is modelled, applying symmetry conditions $\mathrm{Ux}=\mathrm{URy}=\mathrm{URz}=0$ for all nodes at the symmetry plane. 

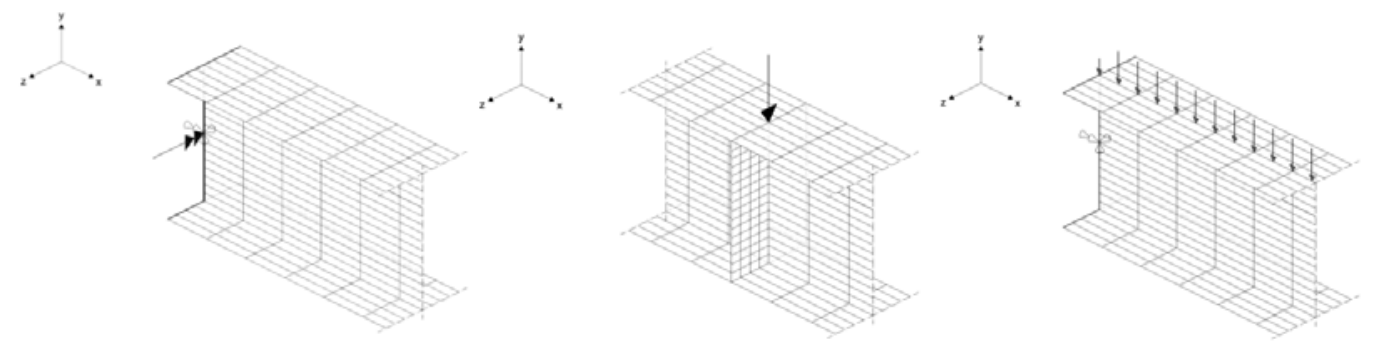

Fig. 3: Load application: LC1 - constant bending moment (left), LC2 - concentrated load (middle), LC3 - uniformly distributed load

Loads are applied as shown in Fig. 3. Note that for the concentrated load, stiffeners have been applied. Linear buckling analyses have been carried out with a Subspace solver, whereas the GMNIA simulations use a modified Riks approach for the solution, with the arc-length size selected such that smooth loaddisplacement curves were obtained.

For the GMNIA, two types of imperfection shapes, i.e. the weak axis FB mode excluding torsion and the LTB mode including torsion are applied after performing the relevant linear buckling analysis (LBA). In Fig. 4 these shapes are shown for the cross-section in the middle of the beam. For the LTB mode the size of the imperfection is measured at the heart of the top flange.

For validation of the finite element model, its GMNIA results were compared with results found in the literature [5, 12], and these results were found to be in good agreement [9].
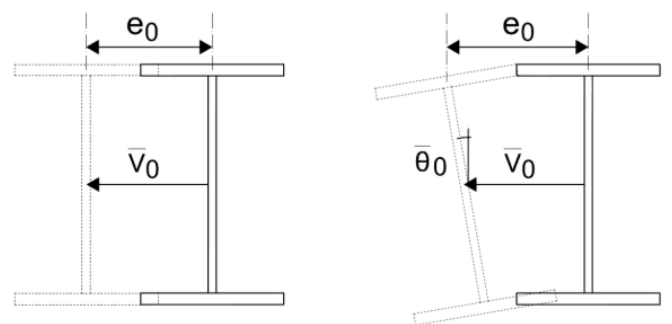

Fig. 4: Two imperfection shapes shown for the cross-section in the middle of the beam: weak axis flexural buckling mode (left), lateral torsional buckling mode (right)

\section{$4 \quad$ Simulation and comparison procedure}

The comparison between the simulations with the finite element method (FEM) and EN 1993-1-1 design rule predictions is illustrated for an IPE240* section with a length of $3400 \mathrm{~mm}$ for load case 1 (constant bending moment) and imperfection approach 2: LTB shape and size of the imperfection according to $k \cdot e_{0, d}$ of Eq. (1). First an LBA is performed resulting in an elastic critical bending moment $M_{c r}=84.1$

kNm. See Fig. 5 for the corresponding buckling mode, which is also used for the shape of the imperfection. Note the half beam model due to symmetry.

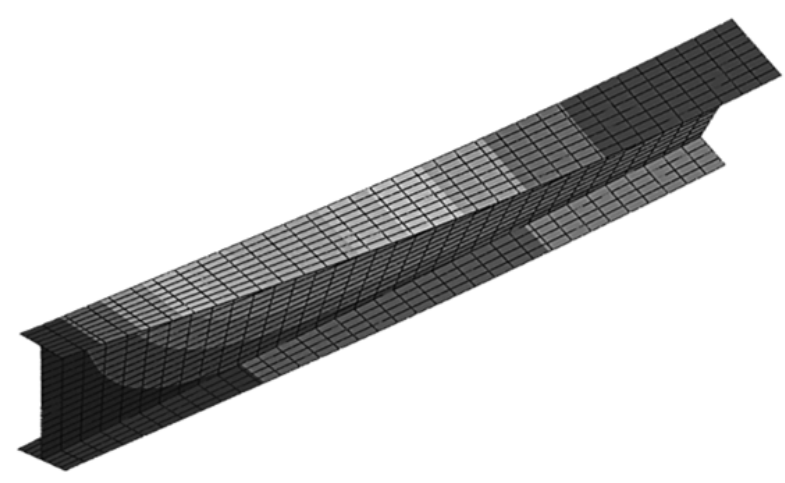

Fig. 5: Half buckling mode shape of a $3400 \mathrm{~mm}$ long IPE240* beam with constant bending moment 
The plastic resistance can be calculated as $M_{p l}=W_{p l y} \cdot f_{y}=353.9 \cdot 103 \cdot 235 \cdot 10-6=83.0 \mathrm{kNm}$. The nondimensional slenderness then equals:

$\bar{\lambda}_{L T, F E M}=\sqrt{\frac{M_{p l}}{M_{c r}}}=\sqrt{\frac{83.0}{84.1}}=0.99$

First the non-dimensional slenderness $\bar{\lambda}$ for weak axis buckling needs to be determined using the elastic critical force for weak axis buckling $N_{c r, z}$ :

$N_{c r, z}=\frac{\pi^{2} E I_{z}}{L_{c r, z}^{2}}=\frac{\pi^{2} \cdot 2.1 \cdot 10^{5} \cdot 282.7 \cdot 10^{4}}{3400^{2}}=506.9 \cdot 10^{3} \mathrm{~N}$

$\bar{\lambda}=\sqrt{\frac{A f_{y}}{N_{c r, z}}}=\sqrt{\frac{3779 \cdot 235}{506.9 \cdot 10^{3}}}=1.32$

In these calculations $I_{z}$ is the weak axis second moment of area, $L_{c r, z}$ is the buckling length for weak axis buckling and $A$ is the area of the cross-section. Since $h / b=240 / 120=2>1.2$ and the flange thickness $t_{f}=$ $9.8 \mathrm{~mm}$ is smaller than $40 \mathrm{~mm}$, buckling curve 'b' applies for weak axis buckling according to Table 6.2 of EN 1993-1-1 and the imperfection factor is $\alpha=0.34$ according to Table 6.1 of EN 1993-1-1. The imperfection size is then determined using Eq. (1):

$e_{0, d}=\alpha(\bar{\lambda}-0.2) \frac{M_{R k}}{N_{R k}}=\alpha(\bar{\lambda}-0.2) \frac{W_{p l, z}}{A}=0.34(1.32-0.2) \frac{72772}{3779}=7.33 \mathrm{~mm}$

With $k=0.5$ the final imperfection size becomes: $3.67 \mathrm{~mm}$. With this imperfection size and the imperfection shape of Fig. 5, a GMNIA is performed, for which load-displacement curves are shown in Fig. 6.

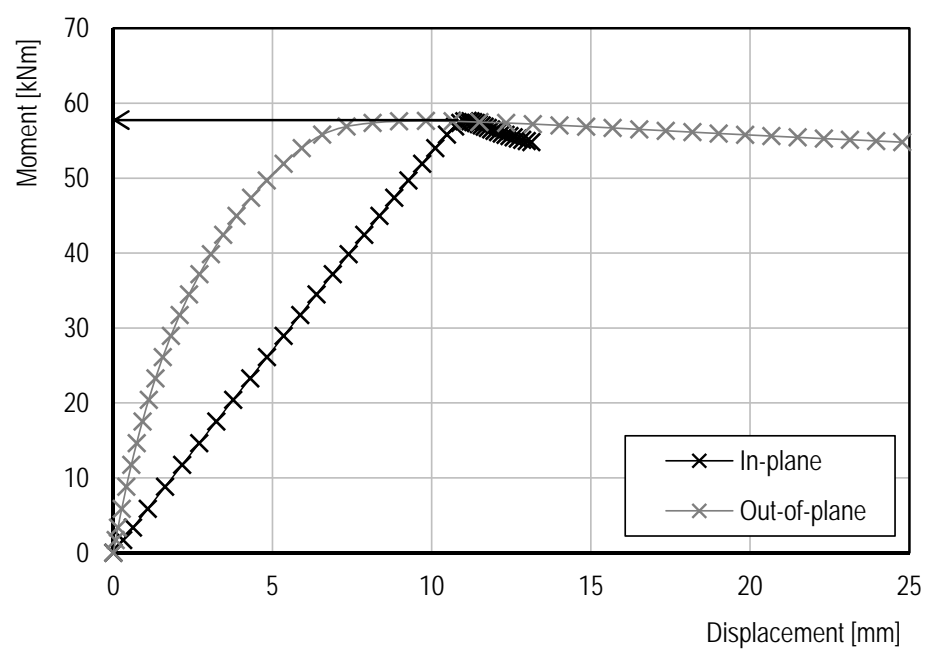

Fig. 6: Load-displacement curves obtained with GMNIA for a 3400 mm long IPE240* beam for LC1, constant bending moment

The ultimate load is reached at $M_{R}=57.6 \mathrm{kNm}$. The reduction factor can then be calculated as:

$\chi_{L T, F E M}=\frac{M_{R}}{M_{p l}}=\frac{57.6}{83.0}=0.694$

The combination of $\bar{\lambda}_{L T, F E M}=0.99$ and $\chi_{L T, F E M}=0.694$ is compared with the current lateral torsional buckling curve ("Curve a") of clause 6.3.2.2 of EN 1993-1-1 as shown in Fig. 7 (black arrows). Results for other values of the non-dimensional slenderness (beam lengths) and other load cases are also included 

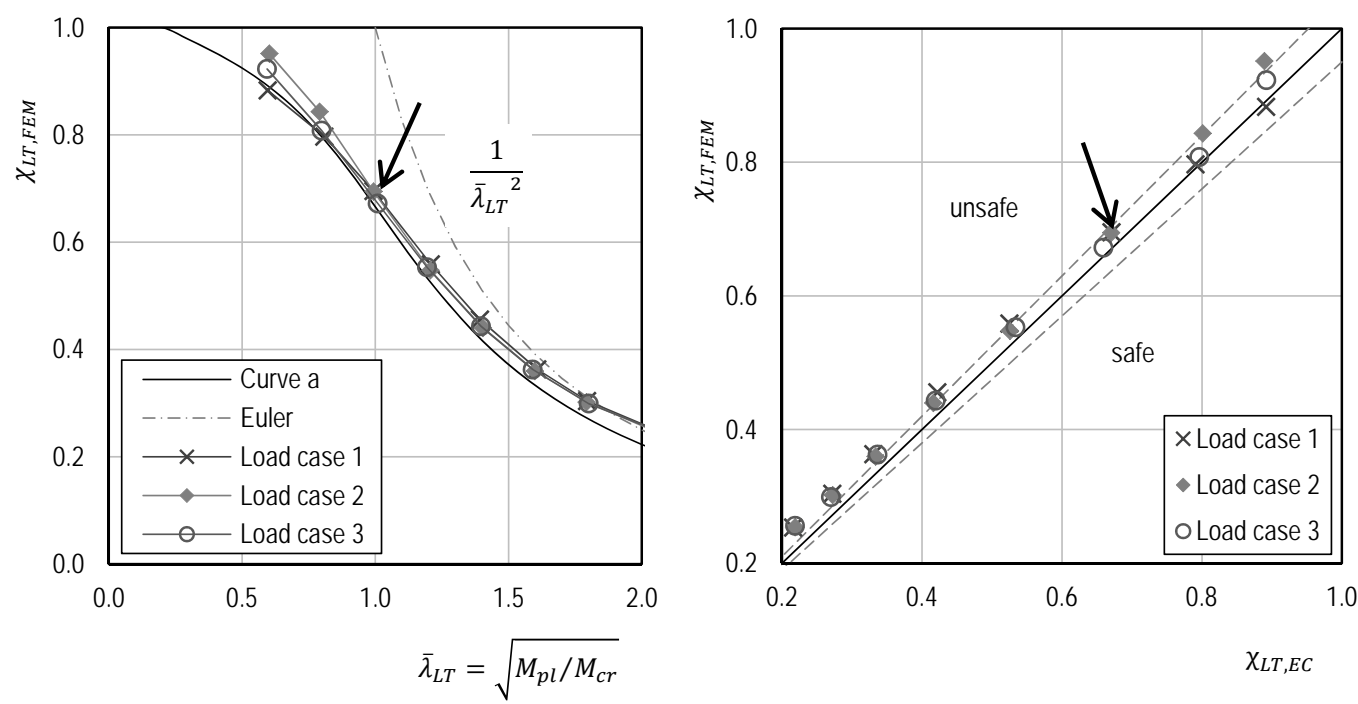

Fig. 7: Comparison of $\chi_{L T, F E M}$ with $\chi_{L T, E C}$ for imperfection approach 2 for an IPE240* beam

in Fig. 7. In Fig. 7 on the left, a direct comparison is made between the FEM results and the buckling curve of EN 1993-1-1. FEM results above the buckling curve are on the unsafe side, i.e. they are calculated using a too small imperfection size so that $k>0.5$ should have been chosen. In Fig. 7 on the right, the reduction factors calculated by FEM are compared with those calculated with the clauses 6.3.2.1 and 6.3.2.2 of EN 1993-1-1. The solid grey line represents a perfect match between both reduction factors. If $\chi_{L T, F E M}>\chi_{L T, E C}$ then the FEM results are on the unsafe side. The two dashed lines represent a 5\% over- or underestimation.

\section{$5 \quad$ Results}

\subsection{Imperfection approach 1: weak axis FB mode with size $k \cdot e_{0}$ of Eq. (1)}

The results for imperfection approach 1, with the imperfection shape based on the weak axis FB mode and the imperfection size equal to $k \cdot e_{0, d}$ of Eq. (1), are shown in Fig. 8 for an IPE600* beam. Similar results were obtained for IPE240* and HEA300* beams, see Fig. 9 [9].
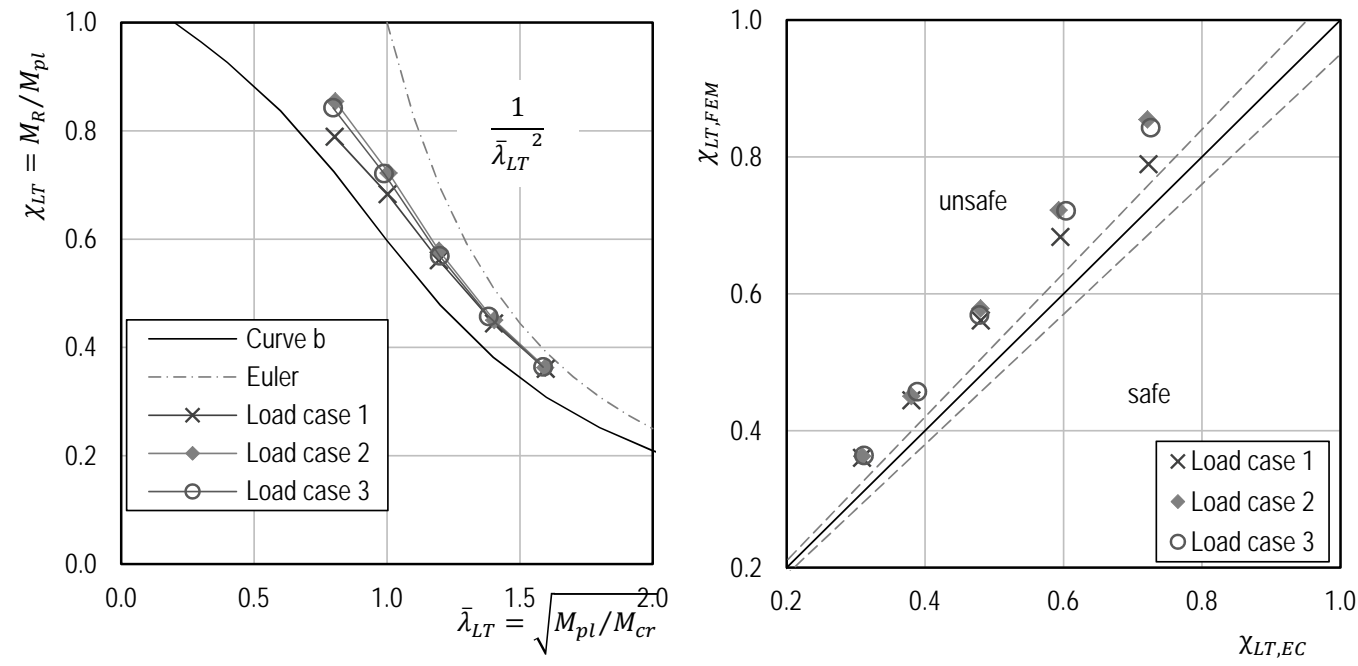

Fig. 8: Comparison of $\chi_{L T, F E M}$ with $\chi_{L T, E C}$ for imperfection approach 1 for an IPE600* beam 

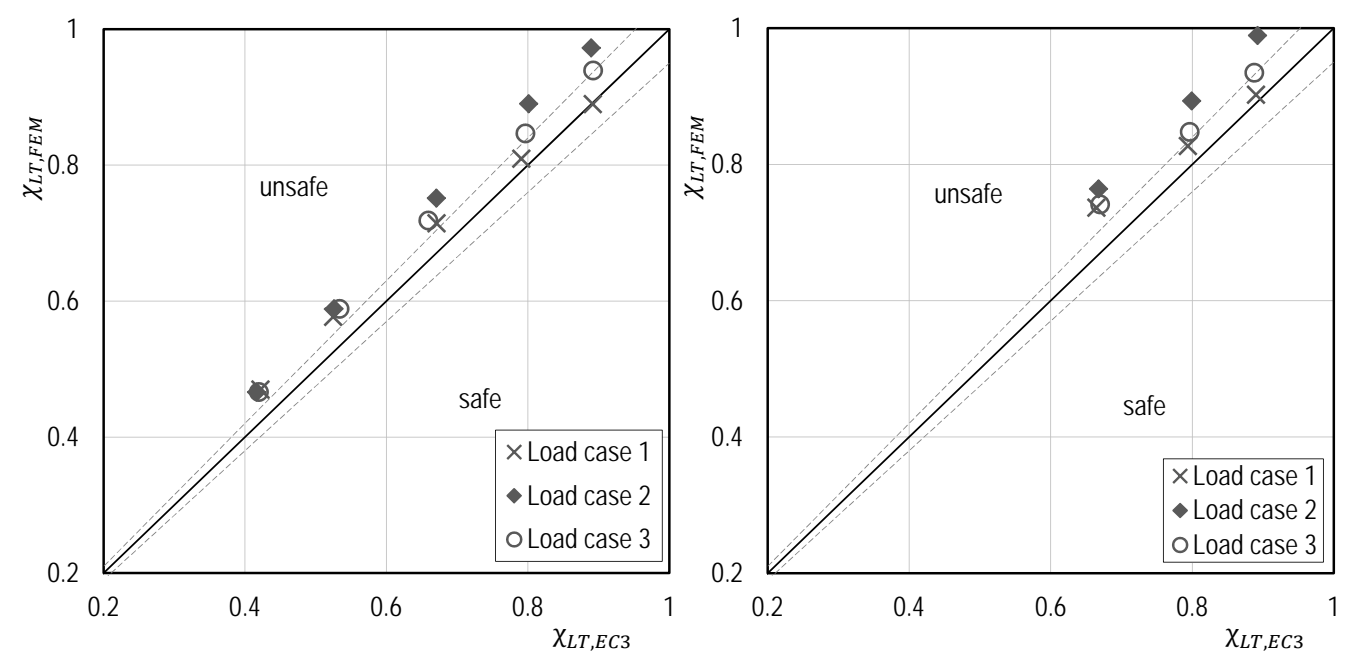

Fig. 9: Comparison of $\chi_{L T, F E M}$ with $\chi_{L T, E C}$ for imperfection approach 1 for an IPE240* beam (left) and an HEA300* beam (right)

As can be seen, load case 2 (concentrated load) gives the largest discrepancies between the FEM and EC3 results. All FEM results are significantly unsafe compared to the EC3 results, meaning that $k=0.5$ is a far too small value. Therefore, it was decided to adjust the $k$-value such that the FEM results are within the $5 \%$ limit boundaries. The analyses concentrated on load case 2 and a relative slenderness equal to 0.9 , for which the influence of imperfections is substantial. Fig. 10 shows for IPE beams the required $k$-values to get $\chi_{L T, F E M}$ to the target value $\chi_{L T, E C}$ as a function of $I_{y} / I_{z}$, where $I_{y}$ is the strong axis second moment of area. These $k$-values range from 2.4 to 1.1 and are summarized in the third column of Table 3. In a similar way adjusted $k$-values for HEA beams were obtained [9], also summarized in Table 3.

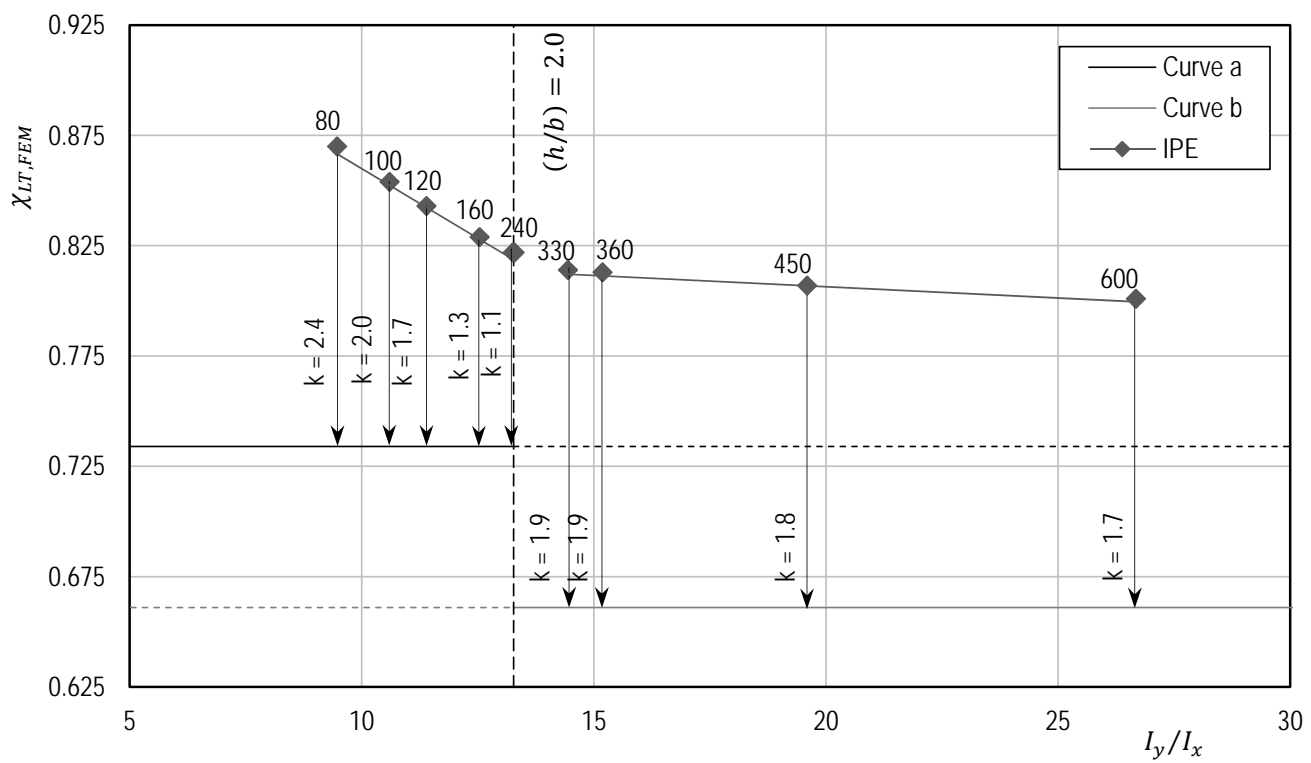

Fig. 10: Required k-values to get $\chi_{L T, F E M}$ to the target value for IPE beams with $\bar{\lambda}_{L T}=0.9$

\subsection{Imperfection approach 2: LTB mode with size $k \cdot e_{0}$ of Eq. (1)}

Fig. 7 shows the results for an IPE240* beam for imperfection approach 2, with the imperfection shape based on the LTB mode, and the imperfection size determined with $k \cdot e_{0, d}$ of Eq. (1). Similar results were obtained for IPE600* and HEA300* beams, see Fig. 11 [9]. In a similar way as described in section 
5.1, required $k$-values were obtained [9]; see the last column in Table 3. The required $k$-values for IPE beams range now from 1.2 to 0.7 [9], still substantially larger than 0.5 , but far better than for imperfection approach 1, for which torsion was neglected, see also Fig. 10.
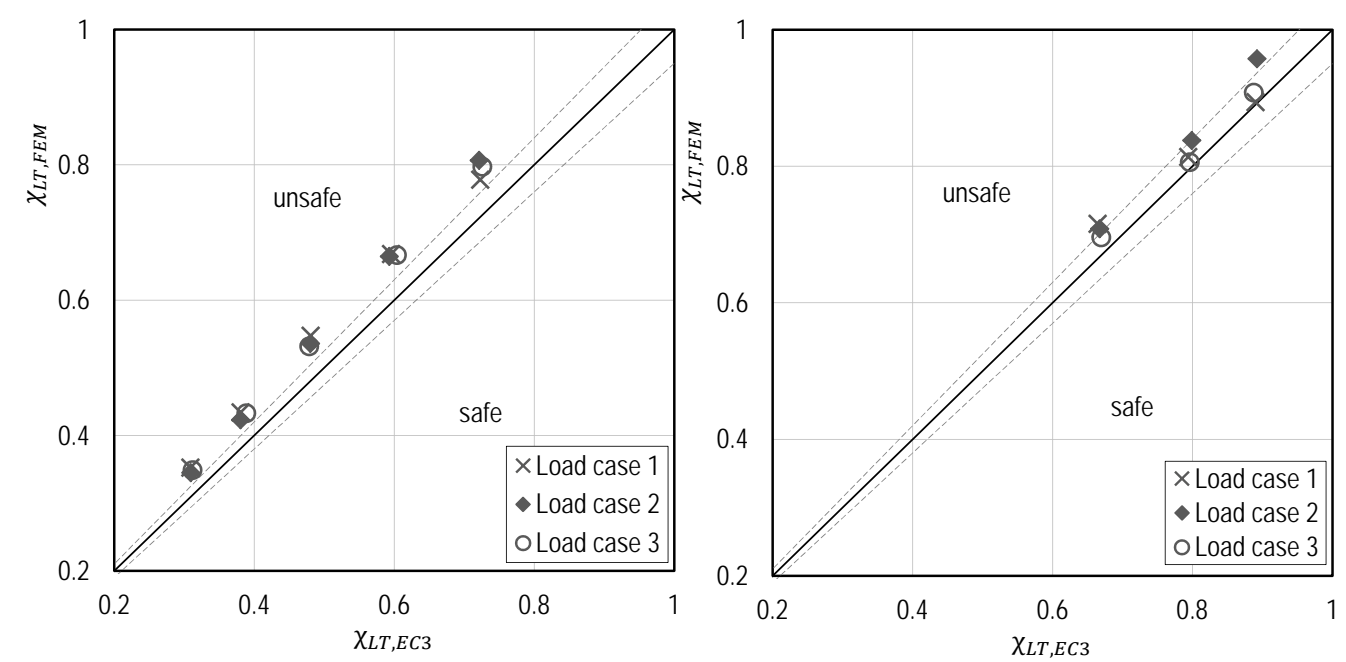

Fig. 11: Comparison of $\chi_{L T, F E M}$ with $\chi_{L T, E C}$ for imperfection approach 2 for an IPE600* beam (left) and an HEA300* beam (right)

Table 3: Required k-values for rolled sections

\begin{tabular}{|l|l|l|l|}
\hline Section & Limits & Imperfection approach 1 & Imperfection approach 2 \\
\hline \multirow{4}{*}{ IPE } & $h / b \leq 2.0$ & $k=-0.34 \frac{I_{y}}{I_{z}}+5.60$ & $k=-0.13 \frac{I_{y}}{I_{z}}+2.44$ \\
\cline { 2 - 5 } & $h / b>2.0$ & $k=-0.017 \frac{I_{y}}{I_{z}}+2.15$ & $k=-0.017 \frac{I_{y}}{I_{z}}+1.44$ \\
\hline \multirow{3}{*}{$H E A$} & $h / b \leq 1.0$ & $k=-6.90 \frac{I_{y}}{I_{z}}+20.40$ & $k=-1.69 \frac{I_{y}}{I_{z}}+5.39$ \\
\cline { 2 - 5 } & $1.0<h / b \leq 1.2$ & $k=-0.11 \frac{I_{y}}{I_{z}}+1.65$ & $k=-0.11 \frac{I_{y}}{I_{z}}+1.05$ \\
\cline { 2 - 5 } & $1.2<h / b \leq 2.0$ & $k=-0.041 \frac{I_{y}}{I_{z}}+1.70$ & $k=-0.027 \frac{I_{y}}{I_{z}}+0.94$ \\
\cline { 2 - 5 } & $h / b>2.0$ & $k=-0.008 \frac{I_{y}}{I_{z}}+2.20$ & $k=-0.008 \frac{I_{y}}{I_{z}}+1.21$ \\
\hline
\end{tabular}

\subsection{Imperfection approach 3: LTB mode with size $e_{0}$ of Eq. (2)}

Figs. 12 to 14 show the results for IPE240*, HEA300* and HEA600* beams respectively, for imperfection approach 3 with the imperfection shape based on the LTB mode, and the imperfection size determined by $e_{0, d}$ of Eq. (2) [9]. For IPE240* beams, all results are satisfactory below the $5 \%$ upper limit. For HEA300* beams with $h / b \leq 1.2$, the results are close to or even slightly above the $5 \%$ upper limit. For HEA600* beams with $h / b \leq 1.2$, the results are on the safe side, within the $5 \%$ lower limit. It can be concluded that this imperfection approach, as could have been expected, leads to consistent results, with the additional benefit that no $k$-value is needed. 


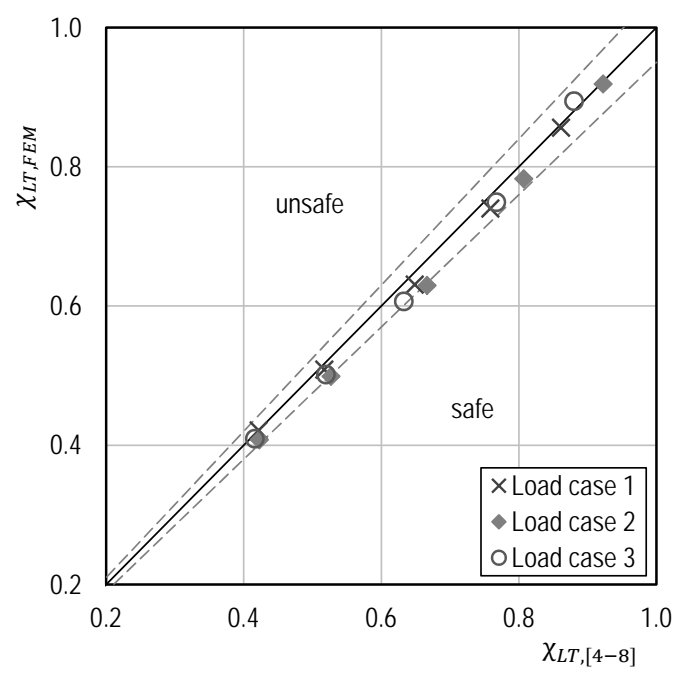

Fig. 12: Comparison of $\chi_{L T, F E M}$ with $\chi_{L T,[4-8]}$ for imperfection approach 3 for an IPE240*

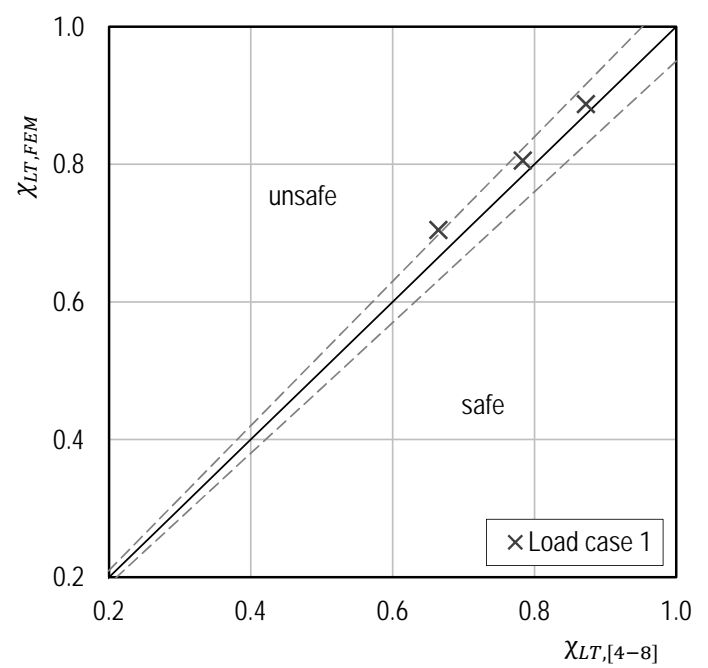

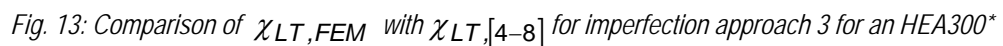

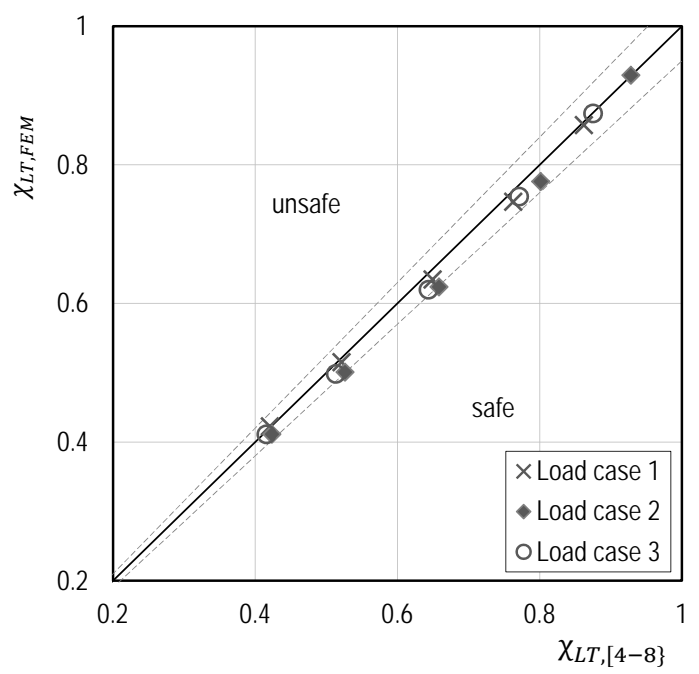

Fig. 14: Comparison of $\chi_{L T, F E M}$ with $\chi_{L T,[4-8]}$ for imperfection approach 3 for an HEA600*

\section{Conclusions}

Three different imperfection approaches have been studied for use in geometrically and materially nonlinear analyses with imperfections for lateral torsional buckling of beams in bending.

It has been shown that imperfection approach 1, using the flexural buckling mode as imperfection shape 
and a factor $k$ multiplied by the initial local bow imperfection of Eq. (1) as imperfection size, requires $k$ values far larger $(k>2)$ than the recommended value $k=0.5$ in cl. 5.3.4(3) of EN 1993-1-1.

Also imperfection approach 2, using the lateral torsional buckling mode as imperfection shape and a factor $k$ multiplied by the initial local bow imperfection of Eq. (1) as imperfection size, requires $k$-values substantially larger than $k=0.5$, the largest value being 1.2, indicating that this approach is an improvement over imperfection approach 1.

Consistent results were obtained for imperfection approach 3, using the lateral torsional buckling mode as imperfection shape and the initial local bow imperfection of Eq. (2) as imperfection size. This imperfection approach does not need a $k$-value and is advised for use in non-linear finite element analyses for lateral torsional buckling.

\section{References}

[1] EN 1993-1-1. Eurocode 3: Design of steel structures- part 1-1: General rules and rules for buildings, Brussels, 2011.

[2] Lindner, J.; Kuhlmann, U.; Just, A.: Verification of flexural buckling according to Eurocode 3 part 1-1 using bow imperfections, Steel Construction 9 (2016), No 4, pp. 349-362.

[3] Lindner, J.; Kuhlmann, U.; Jörg, F.: Initial bow imperfections $e_{0} / L$ of Table 5.1 of EN 1993-1-1, Doc. CEN-TC 250-SC3-WG1 N0155, 2017.

[4] Taras, A.; Greiner R.; Unterweger H.: Proposal for amended rules for member buckling and semicompact cross-section design, Doc. CEN-TC250-SC3_N1898, 2013.

[5] Taras, A.: Contribution to the development of consistent stability design rules for steel members, PhD thesis, Graz University of Technology, Graz, Austria, 2010.

[6] Taras, A.; Greiner, R.: Development of consistent buckling curves for torsional and lateral-torsional buckling, Steel Construction 1 (2008), No 1, pp. 42-50.

[7] Greiner, R.; Taras, A.: New design curves for LT and TF buckling with consistent derivation and code-conform formulation, Steel Construction 3 (2010), No 3, pp. 176-186.

[8] Taras, A.; Greiner, R.: New design curves for lateral-torsional buckling - Proposal based on a consistent derivation, Journal of Constructional Steel Research 66 (2010), pp. 648-663.

[9] Aa, R.P. van der: Numerical assessment of the design imperfections for steel beam lateral torsional buckling, Master thesis, report 2015.96, Eindhoven University of Technology, Eindhoven, Dept. of the Built Environment, Structural Design, The Netherlands, 2015.

[10] Snijder, H.H.; Aa, R.P. van der; Hofmeyer, H.; Hove, B.W.E.M. van: Design imperfections for steel beam lateral torsional buckling, Proceedings of the International Colloquium on Stability and Ductility of Steel Structures, Editors Dan Dubina and Viorel Ungureanu, Wiley Ernst\&Sohn, Published by ECCS, ISBN 978-92-9147-133-1, 2016, pp. 549-556.

[11] Dassault Systems: Simulia Abaqus Unified FEA, Version 6.12, 3DS Business Regions Headquarters, Vélizy-Villacoublay, France.

[12] Bruins, R.H.J.: Lateral torsional buckling of laterally restrained steel beams, Master thesis, report 2007.7, Eindhoven University of Technology, Dept. of the Built Environment, Structural Design, Eindhoven 2007.

Keywords: Lateral Torsional Buckling, Imperfections, Finite Element Analysis, Beams, Eurocode 3 


\section{Authors}

Prof.ir. H.H. Snijder

Eindhoven University of Technology

Department of the Built Environment

Structural Design

P.O. Box 513

5600 MB Eindhoven

The Netherlands

h.h.snijder@tue.nl

Ir. R.P. van der $A a$

Royal HaskoningDHV

Industry \& Buildings

3009 AM Rotterdam

The Netherlands

rob.van.der.aa@rhdhv.com

Dr.ir. H. Hofmeyer

Eindhoven University of Technology

Department of the Built Environment Structural Design

P.O. Box 513

5600 MB Eindhoven

The Netherlands

h.hofmeyer@tue.nl

Ir. B.W.E.M. van Hove

Eindhoven University of Technology Department of the Built Environment

Structural Design

P.O. Box 513

5600 MB Eindhoven

The Netherlands

b.w.e.m.v.hove@tue.nl 